\title{
Exploring A 'Space' For Emergent Learning To Occur: Encouraging creativity And Innovation In The Workplace
}

Genevieve Armson, Curtin University, Australia

\begin{abstract}
This research set out to explore perceptions about the concept of an emergent learning space within private organisations, as the current literature on learning does not adequately differentiate between organised learning and emergent learning. The research objectives explored the existence of, and perceived level of organisational encouragement and support for, emergent learning. Utilising a grounded research approach, the researcher was able to explore how organisations can and do provide a 'space' for emergent learning to occur. In support of social constructionist learning theory, it has shown that this 'space' for emergent learning is strongly influenced by three main factors: the existence of peer discussions, active two-way communications between managers and staff, and a 'have a go' coaching style of management. Constructivist learning theory was supported by the findings that many managers and employees actively seek out opportunities for creativity and innovation, through their own initiative and motivation. Emergent learning is further positively influenced by the existence of and support for organised training programs in the workplace, and the particular company structure and availability of resources. At the edge of chaos, the space for emergent learning was supported by strong two-way communications between managers and staff; the 'have a go' management coaching style; willing peer discussions; ready access to training programs; the company structure and its resources, and the individual's own initiative and motivation. Factors that discouraged the creation of a 'space' for emergent learning to occur were shown to be a resistance to change and insufficient time. The significance of this research lies in two areas. Firstly, the research contributes to the literature on emergent learning in organisations, and provides definition of and support for this type of learning. Secondly, the research assists in the often-cited need for improvement of managerial skills within organisations, by providing managers with ways in which they can ensure their organisations thrive in the 21st century through the active encouragement and support for emergent learning in the workplace.
\end{abstract}

\section{SIGNIFICANCE OF THE CURRENT RESEARCH}

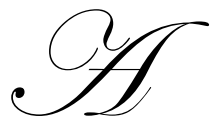

s business enters the 21st century, there is almost universal acknowledgement that the rate of change and the level of complexity faced by organisations is greater than ever before (Dimitriades 2005). Organisations today are experiencing: a faster pace of work and life (Wheatley 1999); a paradoxical phenomenon of predictability and unpredictability (Stacey 2003b); rapid technological changes (Teece et al. 1997); intensified competitive pressures (Schein 1992); unprecedented emphasis on knowledge management (von Krogh et al. 2001), and uncertainty and chaos (Gleick 1998). The dominant quest for most organisations therefore revolves around discovering what will enable them to be successful and competitive in this new and demanding environment. An ever increasing number of studies are now challenging the currently accepted organisational practices and, alternatively, pointing to knowledge management (Nonaka 1994); spiritual capital (Zohar and Marshall 2004); the provision of a space for creativity in organisations (Stacey 1996a); 'intelligent' leadership (Mant 1997) and relationships (Lewin and Birute 2001) as providing the new 'bottom line' of business 
that may lead to a sustainable competitive advantage. Further, Senge (1990b) argues that it is organisational learning that will, in the medium term, be the only source of sustainable competitive advantage. Yet this organisational learning, which is planned, formal and highly structured, can often lead to compliance and an inability of employees to engage in double and triple loop learning (Argyris 1982). The current definition and practice of organisational learning are missing an essential component. Complexity theory gives us a guide as to what is missing in most organisations - a space in which individuals can be creative and innovative; a space where emergent learning can spontaneously occur (Zohar 1994; Stacey 1996a; Gleick 1998); a space where quantum, not just incremental, advances can arise at the edge of chaos (Gleick 1998). The current study is an exploration into this 'space'. Its significance lies in uncovering the organisational conditions that can create this 'space'. Its potential implications for organisations lie in, not simply providing them with yet 'another tool' with which to become more successful in a rapidly changing national and international environment. Much more importantly, the study aims at developing insights that will increase the ability of organisations to move on from materialistic, amoral capitalism (Zohar and Marshall 2004) to a spiritual organisation which truly engages its people in crafting "meaning, values and fundamental purposes" (Zohar and Marshall 2004, p27) for individual and organisational life.

\section{BACKGROUND}

The current research set out to explore perceptions about the concept of an emergent learning space within private organisations. The current literature on learning does not adequately differentiate between the various formats of learning, including structured training programs, on-the-job learning of tasks in an instructional way and management development programs that have specific desired outcomes (Burgoyne and Reynolds 1997). This study, recognising these are all important forms of organised learning, proposed, however, that they are not suitable when individual initiative, creativity or responses to complex and adaptive situations are required. The study focused on the concept of 'emergent learning', relating it to the extant literature on adult learning theories. Further, chaos and complexity theories formed a theoretical underpinning to the research, as organisations were conceptualised as complex adaptive systems (Stacey 1996a).

\subsection{The Changing Nature Of Business In The 21st Century}

The rate of change and the level of complexity faced by organisations in the 21 st century is greater than ever before (Stacey 1996a; van der Sluis 2002). Yet, organisations are now finding that, in an effort to thrive (not merely to survive) in this rapidly changing and complex landscape, the traditional, deliberate organisational strategies, which are competition-based, goal-oriented and often incremental, are no longer sufficient (Jashapara 2003). Faced with these challenges, many organisations are now attempting to discover the factors that will ensure their success in an uncertain and complex environment; to uncover the organisational strategies that will positively impact on corporate performance and proffer them a sustainable competitive advantage. In this knowledge era (Nonaka et al. 2006), organisations that want to go beyond surviving to thriving, need to do more than simply respond to uncertainty and complexity- they need to actively encourage its emergence, while wholly engaging their people in the process (Schein 1992; Phegan 1996).

As the new century emerges, characterised by chaos and complexity (Zohar 1994; Stacey 1996a), the dominant question still remains - what will enable organisations to be successful and competitive? A major component of the answer to this question lies in an organisation's ability to become a learning organisation; to be able to create a culture of engaging people at work, engaging the whole person, not just the work-side of the person (Zohar and Marshall 2004). Phegan (1996) states that those corporate cultures that are highly productive are those in which respect, genuine communications, personal relationships and understanding are visibly in evidence. This implies a new role for top management: a role in which managers "unleash the human spirit, which makes initiative, creativity, and entrepreneurship possible" (Bartlett and Ghoshal 1995, p132). Furthermore, successful organisations are those that empower their employees to learn (Senge 1990b); support them when they make mistakes (Gerber 1998); encourage them to take risks (Alimo-Metcalfe 1996), and recognise their employees as individuals, making a meaningful contribution to the organisation (Bartlett and Ghoshal 1995) A key component in 'empowerment' is the creation of a culture that is based on "purpose, process, and people" (Bartlett and Ghoshal 1995, p142); a culture that encourages and supports emergent learning by its members. 


\subsection{The Learning Imperative}

The imperative for organisations to engage in learning is well accepted in the literature and is reflected by Senge (1990b, front cover insert) when he says that in "the long run, the only sustainable source of competitive advantage is your organization's ability to learn faster than its competition". Research has clearly demonstrated how organisational learning that: is efficient and well-planned (McGill and Slocum Jr 1993); is linked to the work environment (Tannenbaum 1997); recognises learners' experiences and respects their values, opinions and thoughts (Dwyer 2004); is built around the interdependency of individuals (Stacey 2003a); recognises the importance of learner responsibility (Bartell 2001); develops a linkage between the learner and the learning environment (Illeris 2004), and is measured and action-oriented (Taylor et al. 2004) can make a considerable contribution to the organisation's performance.

The current changing and increasingly complex environment in which organisations now operate "demands an unparalleled learning response from organizations" (Bartell 2001, p354). It demands that employee learning include the tacit elements that enable learners to transfer learning to their workplaces. To be competitive, organisations need an awareness that not all learning can be, or perhaps should be, the result of constructed learning experiences. Organisations need to provide a 'space' that permits entrenched belief systems to be overridden so that "our capacity for discovery" (Briskin 1998, p92) is allowed to emerge.

\subsection{The Learning Organisation}

The concept of 'the learning organisation' has received considerable attention and research since it was first defined by Senge (1990b) over 17 years ago. However, over the past few years, the practical application of the learning organisation has been brought into question. Researchers argue that reasons underlying the failed attempts to transform an organisation into a learning organisation include: barriers caused through organisational structures, and managerial actions (Steiner 1998); inconsistent organisation-individual values and mental models (Blackman and Henderson 2005), and, more frequently, a lack of understanding of how adults actually learn in the workplace (Spencer 2002). Senge (1990b, p42) has noted that "when placed in the same system, people, however different, tend to produce similar results".

How adults learn is a complex issue which still, in the 21 st century, generates lively discussions and heated debates. Notwithstanding the considerable attention that adult learning has received, even a cursory examination of the literature on adult learning theory will convince the researcher that, despite many attempts, there is no one unified theory of how adults learn (Illeris 2006; McLean 2006). Given this situation, the researcher examined the extant literature for the various taxonomies for classifying how adults learn, including: the five classical theories of adult learning, namely behaviourism, cognitivism, humanism, social learning and constructivist-social constructionist learning (Merriam and Caffarella 1999); the three learning transactions with adults, that is, andragogy, self-directed learning and transformational learning (Knowles et al. 1998; Merriam and Caffarella 1999), and a meta-classification of adult learning theories (Reese and Overton 1970).

Despite the intense focus on learning in organisations, organised learning and the learning organisation, there is still something missing - for the individual and for the organisation as a whole. Organisations have shown that they are effective at developing learning programs that improve the quality and quantity of the labour output, but how effective have they been at encouraging, developing and supporting the individual's initiative, creativity and innovation (Spencer 2002)? The crisis organisations are facing today is well summarised by Argyris (2001, p109) when he argues that "a generation ago, business wanted employees to do exactly what they were told, and company leadership bought their acquiescence with a system of purely extrinsic rewards...Today, facing competitive pressures an earlier generation could hardly have imagined, managers need employees who think constantly and creatively about the needs of the organisation". In the current changing and increasingly complex environment, organisations need employees who are "flexible and adaptable at work" (van der Sluis 2002, p19). These pressing needs of 21 st century organisations, it is argued, make a case for a 'space' in which employees can feel genuinely empowered to make a difference (Zohar and Marshall 2004); a 'space' in which individuals can be creative, innovative and moderate risk takers; a 'space' in which emergent learning can spontaneously and authentically occur. 


\subsection{The Case For Emergent Learning At The Edge Of Chaos}

"Organizations are creative when their individual members learn and interact creatively with each other in groups" (Stacey 1996a, p165). What is missing in the current view of the learning organisation is the acknowledgement that organisations are not stable, and that emergent learning, resulting in creativity and innovation, takes place within this uncertain environment, on the edge of chaos (Stacey 1996a; Griffin et al. 1999). Kauffman (1995) emphasises the importance of spontaneous self-organisation and emergence in organisational processes. He states that this inevitably leads to aspects of the organisation being unpredictable and uncontrollable.

The exciting discovery to come out of complexity theory is that organisations, viewed as complex adaptive systems "are creative only when they operate in what might be called a space for novelty" (Stacey 1996a, p115). This 'space' is characterised by being at the edge of chaos; by being concurrently in a stable and unstable state (a paradox); by being driven by what seem to be contradictory dynamics of competition and cooperation, amplification and constraint, exposure to creative tension and protection from it. "The defining characteristic of the space for creativity in a group is that it is a state of tension between a legitimate system seeking to sustain the status quo and contain anxiety in the interest of current primary-task performance and a shadow system seeking to undermine that status quo and replace it in the interest of increased fitness" (Stacey 1996a, p163). The result is emergent outcomes or a 'space' in which emergent learning can occur. This area of adult learning, until now, has received minimal research attention, and yet, thoroughly explored, could have significant implications for organisations, for management and for the manner in which workplace learning is viewed and treated. The current empirical research aims to address this gap in the research literature of emergent learning.

\section{RESEARCH QUESTIONS}

The purpose of this research is to explore the existence of, and the level of encouragement and support for, emergent (as opposed to planned or organised) learning in organisations. The research questions were defined as follows:

- how do managers perceive their roles and their employees' roles in creating a 'space' in which the individual can engage in emergent learning?

- how do employees see their roles and the roles of their managers in creating a 'space' in which the individual can engage in emergent learning?

4. RESEARCH OBJECTIVES

The research questions are further defined by the activities chosen as objectives:

- what is meant by emergent learning?

- whether or not employees engage in emergent learning, and

- how organisations can create a 'space' for this to naturally occur.

\section{RESEARCH METHODOLOGY}

The research seeks to gather knowledge from the respondents and acknowledges an interpretative approach to this knowledge gathering. It also assumes that there is little if any distance between researcher and those involved in the research. This is an essential part of the study as it is attempting to discover the employees' lived experiences of organisational life, hence necessitating close contact between the researcher and the actors. This approach thereby demands an interpretative epistemology for this research (Guba and Lincoln 2005).

A qualitative research methodology is employed in this research. This methodology emphasises the formative and inductive nature of a study. It demonstrates that the descriptions of phenomena and their understandings are context-dependent and values-laden (Guba and Lincoln 2005). Using this methodology, the researcher discovers data and then works inductively to develop categories of information (Creswell 1998). A design or theory of the phenomena thereby emerges. This is referred to as the emergent nature of the qualitative methodology (Bryman 1988). This study explores the phenomenon of 'emergent learning', as experienced by 
managers and employees in their workplaces. It also analyses the data collected from managers and employees and inductively analyses and categories this data. Thus a qualitative research paradigm was selected as most appropriate.

This research, therefore, employs a constructivist, interpretative, qualitative approach. The theoretical perspectives of phenomenology and grounded theory were considered the most appropriate for this study. Phenomenology allows the qualitative researcher to achieve the aim of recording "the processes by which social reality is constructed, managed, and sustained" (Holstein and Gubrium 2005, p483). A grounded theory approach was utilised by the research as it results in a theory "that is inductively derived from the study of the phenomenon it represents. That is, it is discovered, developed, and provisionally verified through systematic data collection and analysis of data pertaining to that phenomenon. Therefore, data collection, analysis, and theory stand in reciprocal relationship with each other" (Strauss and Corbin 1990, p23). Grounded theory provides the researcher the opportunity to focus on data collection; to successively and simultaneously analyse the data, to utilise constant comparison and to develop concepts that show processual relationships (Charmaz 2005). Although grounded theory is now a well-accepted and widely-used qualitative research approach, its direct applicability to the business setting has been brought into question by Whiteley (2004). As a result of the modifications to grounded theory that evolved during her 2004 study, she subsequently coined the term 'grounded research' - grounded theory as applied to business research studies. Essentially, these modifications addressed the emergent need to "collect accounts of multiple social realities" (Whiteley 2004, p38); and to recognise that, in contrast to pure grounded theory, "some forcing of constructs will usually happen simply because of the existing meaning, structures and functions operating as the organizational framework" (Whiteley 2000, p5). Further, grounded research acknowledges the need for the researcher to understand the organisational hierarchies, tasks, roles and language by undertaking a familiarisation study prior to the progress of the research. These organisational constructs or pre-existing bounded categories may not be able to be ignored during a qualitative study in a business setting (Whiteley 2000). Given the business setting of the current study, a grounded research approach was considered appropriate.

The familiarisation study in the current research had four specific purposes: to determine the most appropriate style of questions in order to elicit sufficient rich data; to ensure all research terms would be clearly understood by the prospective interviewees; to raise the researcher's awareness of her own assumptions, biases and preconceptions in undertaking this research; and to "absorb tacit knowledge, conventions, ways of communicating, rituals, stories, lore" within the organisation being studied (Whiteley 2002, p11). The data analysis stage began as soon as data collection commenced. Theoretical coding, referred to by Glaser and Strauss (1967) as theoretical sensitivity, was utilised throughout the research. Bracketing or epoché, the "process of suspending prior expectations" (Sim and Wright 2000, p 151) was acknowledged as part of this stage of the process. Software (QSR $\mathrm{NVivo}_{7}$ ) was used to collect, manage and interrogate the qualitative data in this research project.

\section{FINDINGS}

The research questions (refer section 3) were used as the basis for the development of the interview questions used in the semi-structured interviews with users and creators of the 'space' for emergent learning.

The research has shown that a 'space' for emergent learning does indeed exist in the workplaces of the respondent organisations and is encouraged and supported by: strong two-way communications between managers and staff; willing peer discussions; ready access to training programs; the company structure and its resources, and the individual's own initiative and motivation. Barriers to this 'space' were shown to be a resistance to change and insufficient time. The relationship between the research objectives/questions and the interview questions is shown in figure 1. The findings were initially coded into categories which represented the interview questions that were asked of the creators (eight questions) and the users (10 questions) of the 'space' for emergent learning. On deeper analysis and by utilising constant comparison of these initial categories, the findings in these categories were then recategorised into new and emergent categories for the managers' responses and for the employees' responses. The managers' responses were categorised into their perception of their role and their perception of the role of the employees. These were further categorised into items that encourage emergent learning, items of which they could do more, and items of which they could do less, in order to encourage emergent learning in the workplace. A similar categorisation for the employees' responses was developed. The final categorisation of the findings is shown in figures 2 and 3. 


\section{Figure 1 Development of the interview questions}

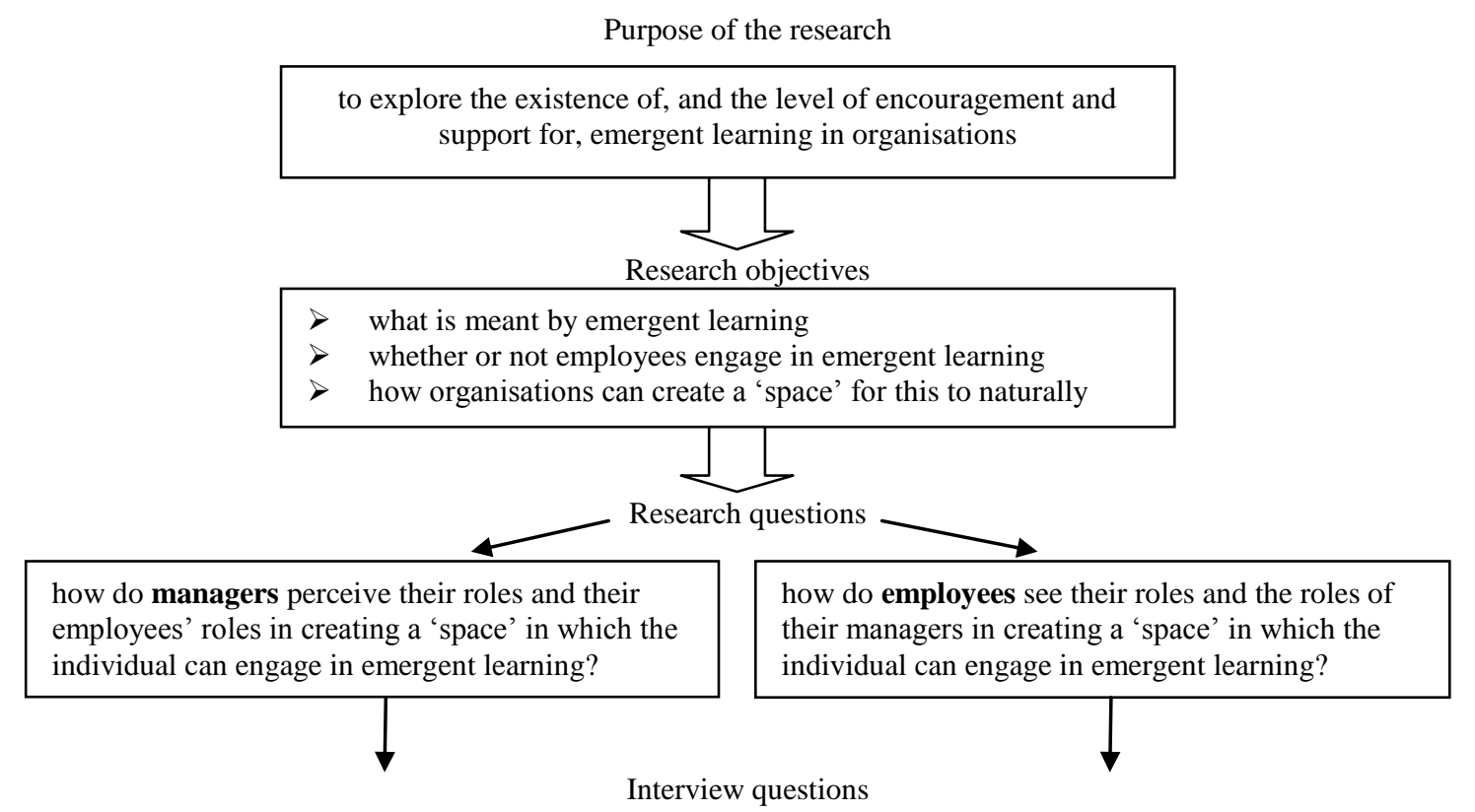

- What does the company do to encourage your learning?

- What things in the company help you in being creative, to be spontaneous, to come up with and run with new ideas, to take risks?

- What things in the company stop or hinder you from being creative, being spontaneous, coming up with and runningwith new ideas, taking risks in your job?

- It's Monday morning and over the weekend one of your team members had a great idea for a better way to do something related to their job at (company name). They put the idea to you. However, you think it would involve some risk (money, time, success not guaranteed). What would be your typical response? Why?

- Let's say one of your staff has been doing their job for some time. You know they feel confident and comfortable with their job - you are confident they know how to do it, and know what outcomes and standards are expected of them. Then you notice that they have changed one of the procedures in their job and this new method has resulted in mistakes and stuff ups. You hadn't been consulted about the change. What is your response to them?

- To encourage my staff to learn more in the workplace, I do.....

- To encourage my staff to be more creative and innovative in the workplace, to come up with and run with new ideas, I could do more of...

- In terms of my staff learning more on the job, I would like to see them doing more of...
- What does the company do to encourage your learning?

- What things in the company help you in being creative, to be spontaneous, to come up with and run with new ideas, to take risks?

- What things in the company stop or hinder you from being creative, being spontaneous, coming up with and running with new ideas, taking risks in your job?

- It's Monday morning and over the weekend you had a great idea for a better way to do something related to your job at (company name). You put this to your colleagues. What would be their typical response?

- It's Monday morning and over the weekend you had a great idea for a better way to do something related to your job at (company name). You put this to your direct manager. What would be his/her typical response?

- Let's say your direct manager thought it was a great idea but it does involve some risks (money, time, success not guaranteed). What would your manager do/say about your idea now?

- When I suggest a new idea to my direct manager, her/his response is...

- If I were to implement a new idea in my job without discussing it with my manager, her/his typical response would be...

- To encourage me to be more creative and innovative to come up with and run with new ideas - in my job, management currently do...

- To encourage me to be more creative and innovative to come up with new ideas - in my job, management could do more of... 
Figure 2 Final categorisation for the construct of managers' perceptions

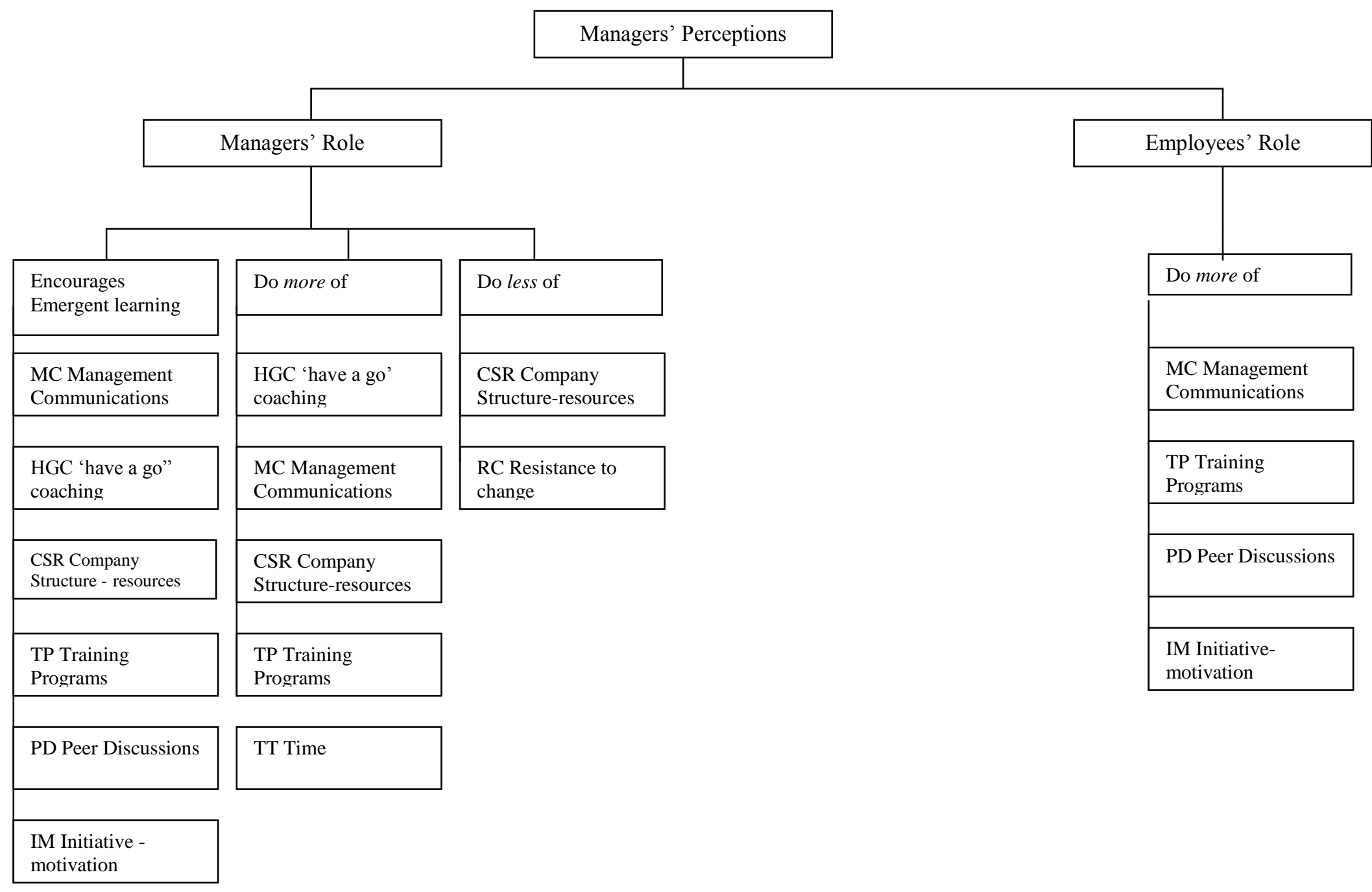


Figure 3 Final categorisation for the construct of employees' perceptions

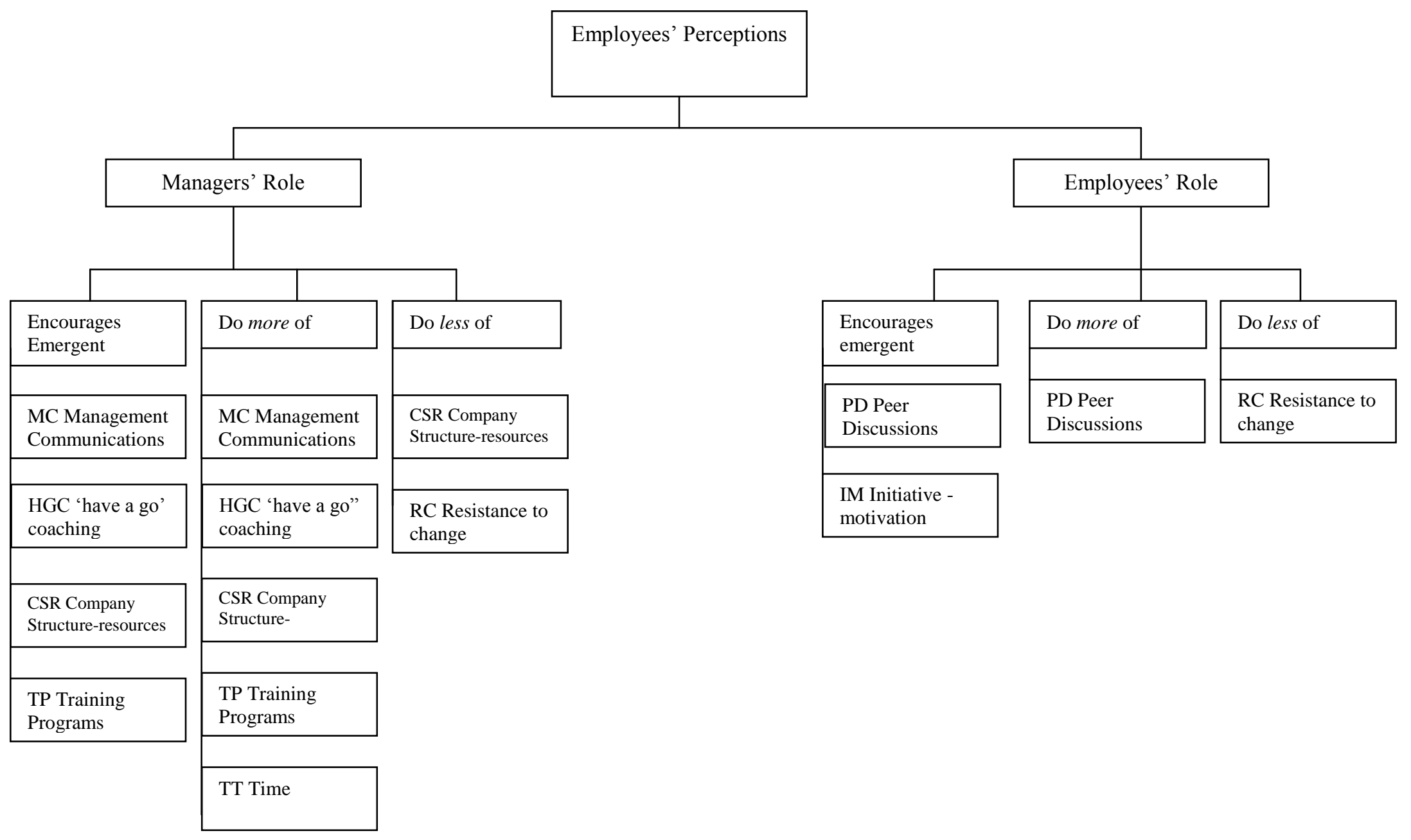




\section{DISCUSSION}

The original purpose of this research was to explore the existence of and support for emergent learning in the workplace. However the findings strongly supported the existence and value of organised learning as an integral part of emergent learning.

The conceptual framework represented in figure 4 contains the theories that were considered relevant to the research. The findings from this research were strongly sensitive to, and resonated with, the constructivist theory of learning, the social constructionist theory of learning and the theory of complexity as applied to organisations. Further, the space for emergent learning was a direct result of an environment comprising several cultural enablers including: strong listening skills on the part of the managers; a 'have a go' approach by the managers, thereby encouraging their staff to develop and experiment with new ideas; dialectic between managers and staff; coaching of the staff by the managers, and a strong peer network, supportive of open and candid discussions. The factors that discouraged a 'space' for emergent learning, as supported by the current research, were resistance to change and a lack of time; both factors being experienced and commented on by managers and employees.

Figure 4 Theoretical perspectives supported by the findings of this research

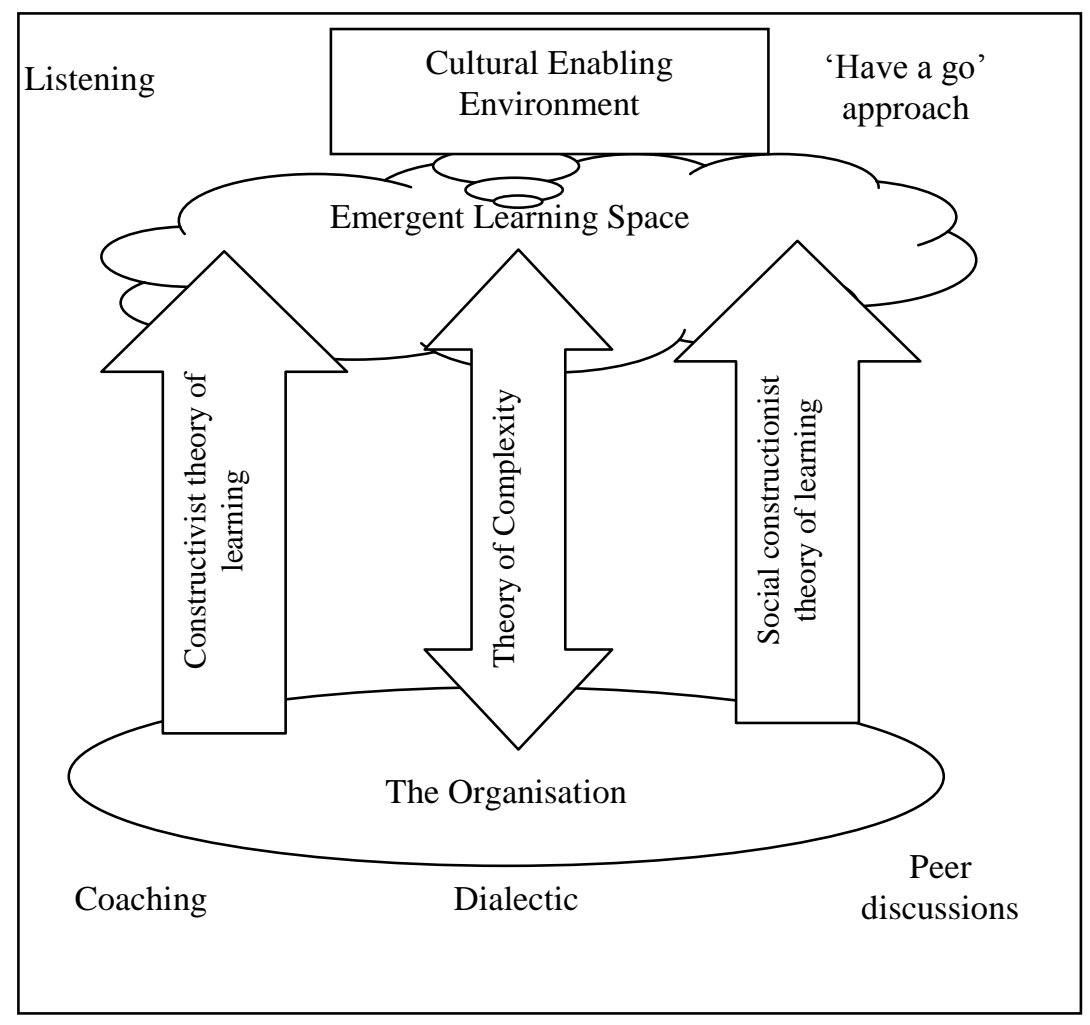

The findings' categories that emerged from this research are graphically represented in figure 5. These categories are superimposed on the theories that are supported by, and sensitive to, this research. The constructivist theory of learning was supported by the category of initiative-motivation (IM); the social constructionist theory of learning was supported by the categories of management communications (MC), 'have a go' coaching (HGC), peer discussions (PD), training programs (TP) and company structure-resources (CSR). The theory of complexity was supported by the categories of management communications (MC), 'have a go' coaching (HGC) peer discussions (PD), initiative-motivation (IM), training programs (TP), and company structure-resources (CSR). The findings' 
categories that detracted from a space for emergent learning, in complexity theory, were resistance to change (RC) and lack of time (TT).

Figure 5: Theoretical sensitivity of the findings' categories

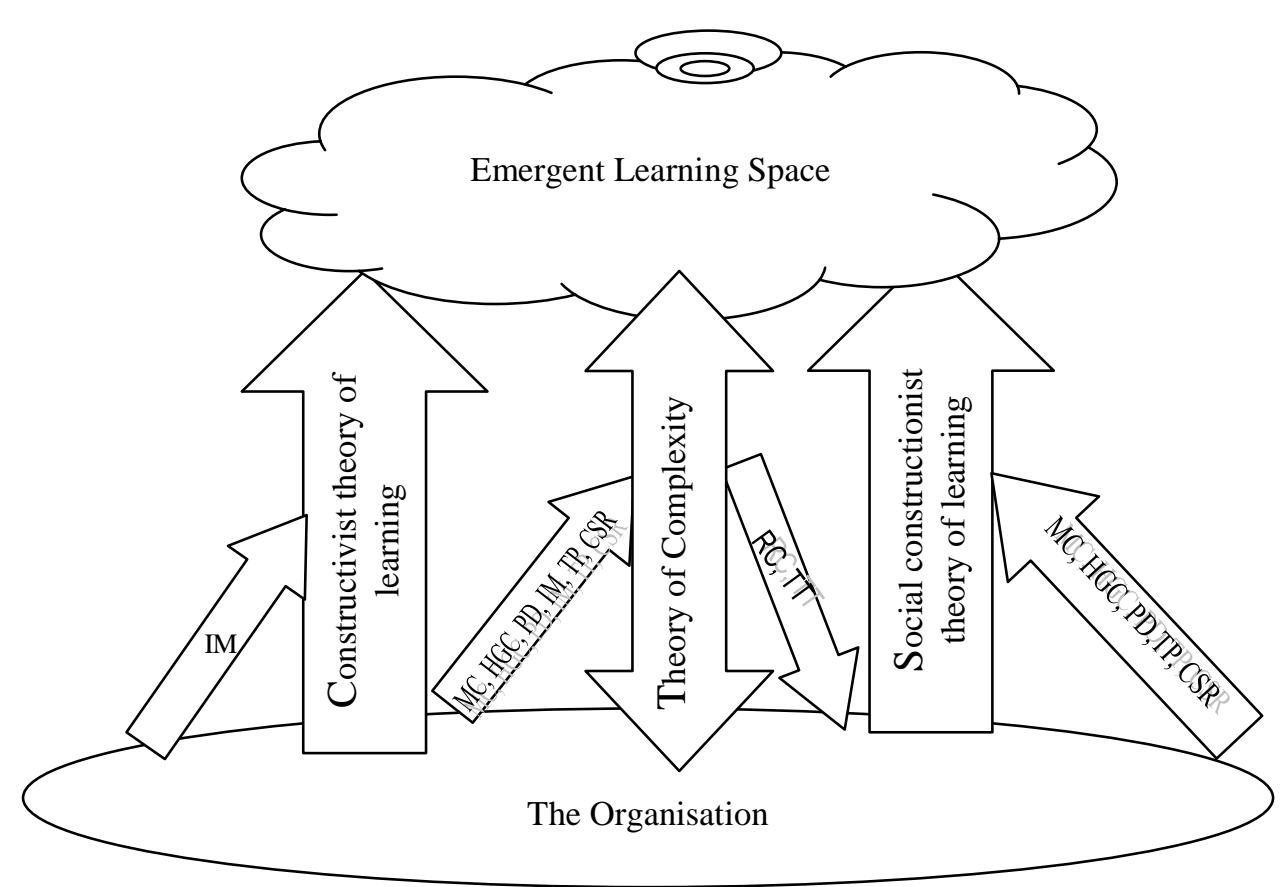

\subsection{Learning Occurs In A Constructivist - Social Constructionist Continuum}

The theory of social constructionist learning emphasises the learning process as being influenced by dialogue with others (Berger and Luckmann 1966); based on making sense of one's experiences, and occurring in the social setting (Shotter 1993). Social constructionism is, thereby, "principally concerned with explicating the processes by which people come to describe, explain, or otherwise account for the world (including themselves) in which they live" (Gergen 1985, p266). In essence, it is concerned with how people learn through the construction of meaning of their everyday experiences (Merriam and Caffarella 1999). In line with this theory, the current research was concerned with how managers and employees described, viewed and accounted for a space for emergent learning in their workplaces.

The term 'social constructionism' or 'social constructivism' to which it is sometimes referred (Candy 1991) does not, however, refer to one, unified theory, but to a cluster of perspectives that span a range of disciplines including psychology, education, sociology, mathematics and anthropology (Phillips 1995). The basic tenet for social constructionism is that knowledge is constructed (Bohan 1990). Yet, beyond this core assumption, the various perspectives of social constructionism differ on several issues: the nature of reality, the role experience plays in the learning process, what knowledge is of interest, and whether the process of meaning making is primarily individual or social (Cobb 1994; Steffe and Gale 1995). Thus learning in a social constructionist paradigm can be viewed along various axes or continua. These axes represent three questions in relation to how learning occurs. Firstly, how is knowledge constructed? secondly, how does new knowledge occur? and finally, what is the role of the learner in the learning process? Figure 6 illustrates the findings overlaid on these axes. 


\section{Figure 6: Support for constructivist-social constructionist learning continua}

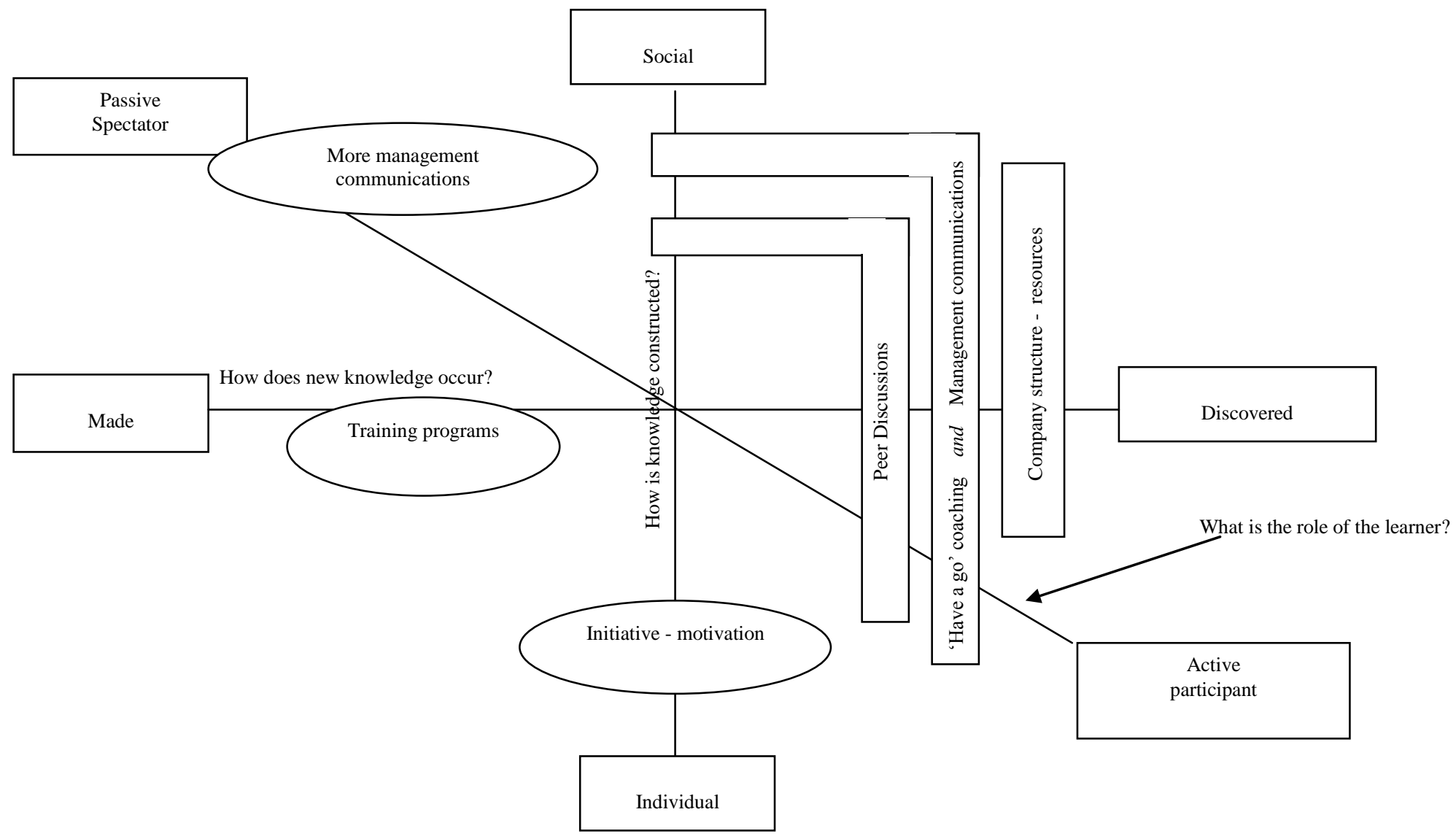


A social constructionist, social-context locus of learning perspective was strongly supported by the findings' categories of 'management communications', 'have a go' coaching and 'peer discussions' while the constructivist (focus on individual in the process of learning) was strongly supported by the findings category 'initiative-motivation'. How the findings support this constructivist $\leftrightarrow$ social constructionist theory of learning continuum is illustrated in figure 7. Further, it can be claimed that the findings' category 'have a go' coaching serves as a pathway or bridge along this continuum. The category of 'peer discussions' also has a reciprocal and synergistic relationship to the category 'initiative-motivation'.

Figure 7: Support for learning from an individual to a social locus

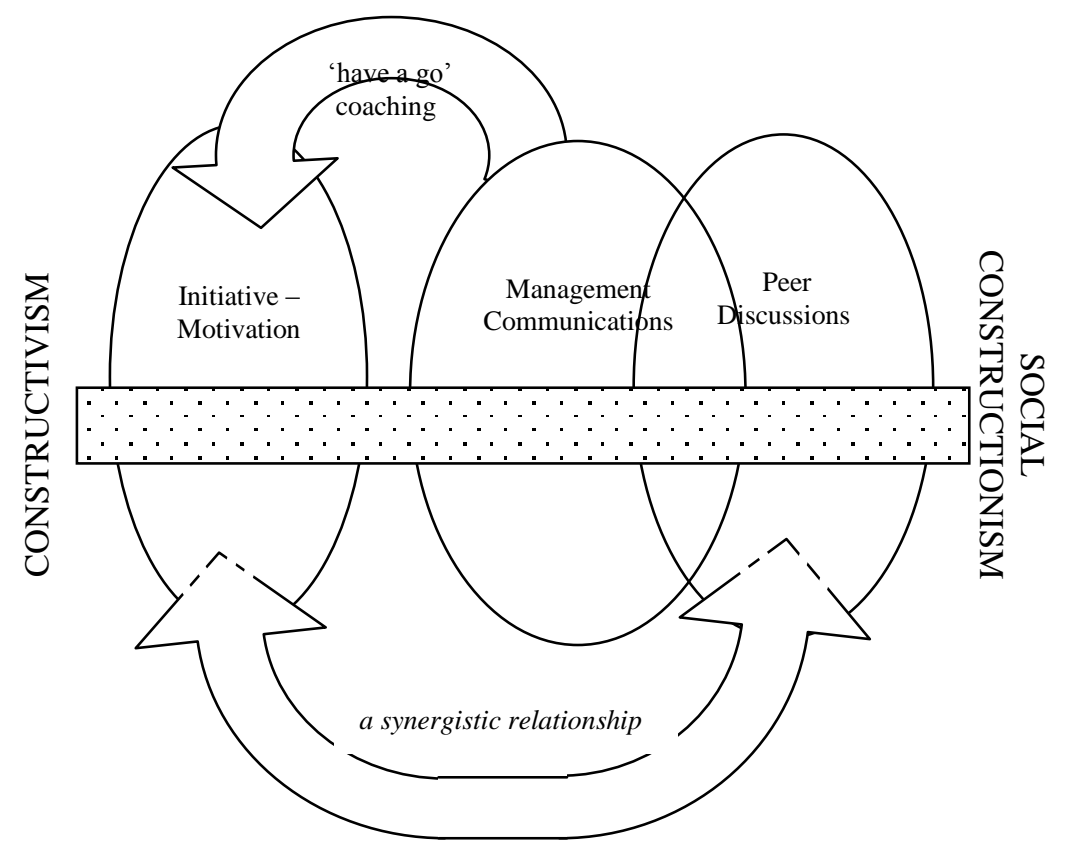

The second dimensional continuum of the constructionist view of learning explores the question 'how does new knowledge occur?' The view of knowledge being made was moderately supported by the findings category 'training programs' as the responses by managers and by employees reflected a genuine commitment to organised learning by the companies involved in this research. The view of knowledge as being discovered - with the managers and employees as 'discoverers' - was supported by the findings categories 'management communications', 'have a go' coaching, and 'peer discussions'. Further, the managers and the employees commented on how the company structures and resources 'minimally constrained' their abilities to learn through discovery. These latter comments are reflected in the findings category 'corporate structure and resources'.

The third, and final dimension or axis, along which the social constructionist theory of learning was explored, relates to the role of the learner in the learning process. This role can be viewed as a continuum from the learner as a passive spectator through to the learner as an active participant (Phillips 1995). The findings' category 'more management communications' only weakly supported the 'learner as passive spectator' view of learning, while the findings' categories of 'management communications', 'have a go' coaching and 'peer discussions' strongly supported the 'learner as an active participant' social constructionist view of learning.

\subsection{Support And Challenge For The Organisation As A Complex Adaptive System}

The science of complexity is intensely concerned with the fundamental properties of open, dynamic and nonlinear-feedback networks and particularly of complex adaptive systems (Stacey 1996a). Organisations, their dynamics, structure and creation of, and responses to, the constant state of change, can now be more fully understood and explained in terms of this new science of complexity. More specifically, organisations can now be viewed as complex adaptive systems (Stacey 1996b), that is, systems consisting of a number of interacting 
components, or agents, acting in accordance with sets of rules or schemas. These interactions within the complex adaptive system lead each component, thus the system as a whole, to learn "its way into the future" (Stacey 1996b, p183). Furthermore, a complex adaptive system is one that has acquired the unique ability to be poised on the brink between order and chaos, giving rise to an equilibrium point or the edge of chaos (Burnes 1996). It is at this edge of chaos - this "space for novelty" - that spontaneity, creativity, adaptation and innovation occur (Stacey 1996a, p115). The findings from this research stand in support of this view of the organisation as a complex adaptive system, engaged in evolving, as its agents are absorbed, at the edge of chaos, in emergent learning. The conceptual framework presented in figure 8 represents this view of the organisation as a complex adaptive system, emergently creating and learning, at the edge of chaos. This emergent learning is supported and encouraged by the organisational characteristics, embodied in the findings categories of 'management communications' (MC), 'have a go' coaching (HGC), 'peer discussions' (PD), 'training programs' (TP), 'initiative-motivation' (IM) and 'company structure and resources' (CSR). The research also demonstrated that these characteristics of the organisation, its structure and its people, encouraged management and the employees to question the status quo, to move from order, and learn at the edge of chaos. Further, the findings categories of 'time' (TT) and 'resistance to change' (RC) represented characteristics of the organisations that maintained the managers and the employees in the status quo or order, and withheld them from moving towards, and learning at, the edge of chaos.

Figure 8 Findings support the organisation as a complex adaptive system

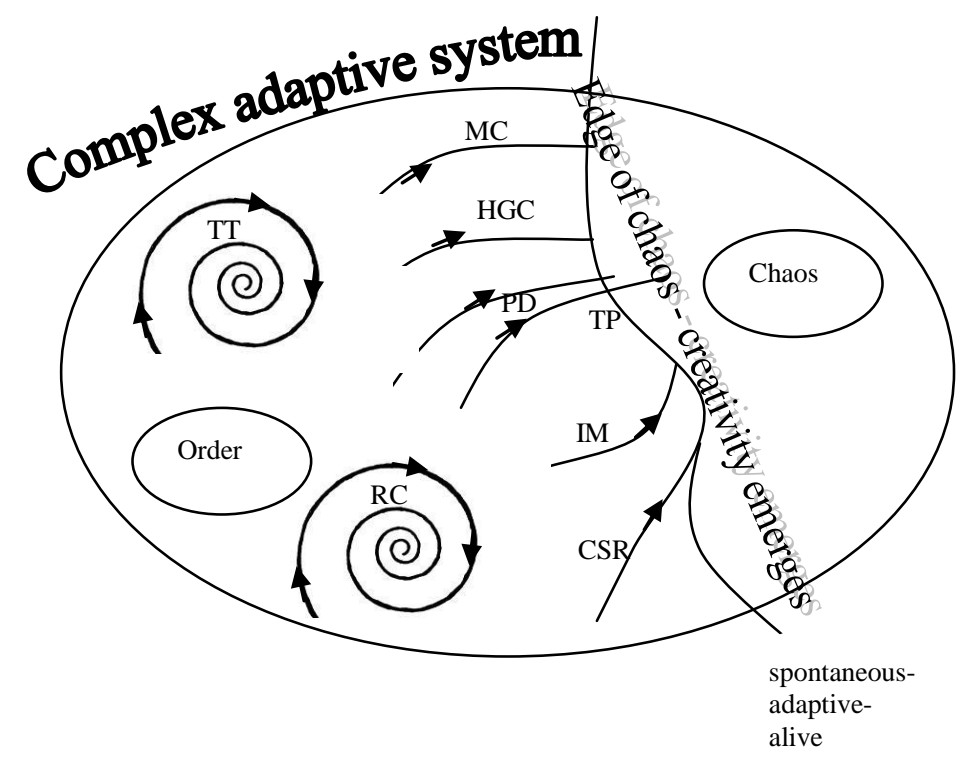

$\mathrm{MC}=$ management communications; $\mathrm{HGC}=$ 'have a go' coaching; $\mathrm{PD}=$ peer discussions;

$\mathrm{TP}=$ training programs; $\mathrm{IM}=$ initiative-motivation; $\mathrm{CSR}=$ company structure and resources;

$\mathrm{TT}=($ lack of $)$ time, and $\mathrm{RC}=$ resistance to change

\section{CONCLUSION}

This research has demonstrated the existence of a 'space' in which emergent learning can and does occur in the workplace. In support of social constructionist learning theory, it has shown that this 'space' for emergent learning is strongly influenced by three main factors: the existence of peer discussions, the active two-way communications between managers and staff, and a 'have a go' management coaching style. Constructivist learning theory was supported by the findings that many managers and employees actively seek out opportunities for creativity and innovation through their own initiative and motivation. From these latter findings, it has been argued that the 'space' for emergent learning is also a self-creation: it is self-created by the managers and employees 
through their respective desires and initiatives to learn, to experiment and to take moderate risks. Emergent learning, undertaken by managers and employees, is further positively influenced by the existence of and support for organised training programs in the workplace, and the particular company structure and availability of resources.

At the edge of chaos, the space for emergent learning was supported by strong two-way communications between managers and staff; a 'have a go' management coaching style; willing peer discussions; ready access to training programs; the company structure and its resources, and the individual's own initiative and motivation. Through these findings, the theory of complexity, as applied to organisations viewed as complex adaptive systems, was supported.

\section{REFERENCES}

1. $\quad$ Alimo-Metcalfe, Beverly (1996). "Machiavelli, Mother Teresa and the concept of empowerment." Human Resources Management International Digest 4(1): 36-39.

2. $\quad$ Argyris, Chris (1982). "The executive mind and double-loop learning." Organizational Dynamics Autumn: 5-22.

3. Argyris, Chris (2001). Good communication that blocks learning. Harvard Business Review on Organizational Learning. USA, Harvard Business School Publishing Corporation.

4. Bartell, Sherrie Myers (2001). "Training's new role in learning organizations." Innovations in Education and Teaching 38(4).

5. Bartlett, Christopher A. and Sumantra Ghoshal (1995). "Changing the role of top management: Beyond systems to people." Harvard Business Review May-June.

6. Berger, Peter L. and Thomas Luckmann (1966). The social construction of reality: A treatise in the sociology of knowledge. Harmondsworth, Penguin.

7. Blackman, Deborah and Steven Henderson (2005). "Why learning organisations do not transform." The Learning Organization 12(1): 42-57.

8. Bohan, Janis S. (1990). "Social constructionism and contextual history: an expanded approach to the history of psychology." Teaching of Psychology 17(2): 82-89.

9. Briskin, Alan (1998). The stirring of soul in the workplace. San Francisco, USA, Berrett-Koehler Publishers, Inc.

10. Bryman, Alan (1988). Chapter 3. The debate about quantitative and qualitative research. Quantity and quality in social research. London, UK, Routledge.

11. Burgoyne, John and Michael Reynolds (1997). Management learning: integrating perspectives in theory and practice. London, Sage Publications.

12. Burnes, Bernard (1996). Managing change: a strategic approach to organisational dynamics. London, UK, Pitman.

13. Candy, Phillip C. (1991). Self-direction for lifelong learning. San Francisco, California, USA, Jossey-Bass Inc.

14. Charmaz, Kathy (2005). Grounded theory in the 21st century. The Sage Handbook of Qualitative Research. N. K. Denzin and Y. S. Lincoln. California, USA, Sage Publications, Inc.

15. Cobb, Paul (1994). "Where is the mind? Constructivist and sociocultural perspectives on mathematical development." Educational Researcher 23(7): 13-20.

16. Creswell, J.W. (1998). Chapter 5. Philosophical and theoretical frameworks. Qualitative inquiry and research design. Thousand Oaks, California, USA, Sage.

17. Dimitriades, Zoe S. (2005). "Creating strategic capabilities: organizational learning and knowledge management in the new economy." European Business Review 17(4): 314-324.

18. Dwyer, Rocky J. (2004). "Employee development using adult education principles." Industrial and Commercial Training 36(2/3): 79.

19. $\quad$ Gerber, Rod (1998). "How do workers learn in their work?" The Learning Organization 5(4): 168.

20. Gergen, K.J (1985). "The social constructionist movement in modern psychology." American Psychologist March: 266-275.

21. Glaser, B and A Strauss (1967). The discovery of grounded theory: Strategies for qualitative research. Chicago, USA, Aldine Publishing Co.

22. Gleick, James (1998). Chaos. London, UK, Vintage. 
23. Griffin, Douglas, Patricia Shaw and Ralph Stacey (1999). "Knowing and acting in conditions of uncertainty: A complexity perspective." Systemic practice and action research 12(3): 295.

24. Guba, Egon G. and Yvonna S Lincoln (2005). Paradigmatic controversies, contradictions, and emerging confluences. The Sage handbook of qualitative research. N. K. Denzin and Y. S. Lincoln. California, USA, Sage Publications, Inc.

25. Holstein, James A. and Jaber F. Gubrium (2005). Interpretive practice and social action. The Sage Handbook of Qualitative Research. N. K. Denzin and Y. S. Lincoln. California, USA, Sage Publications, Inc.

26. Illeris, Knud (2004). "A model for learning in working life." Journal of Workplace Learning 16(7/8): 431441.

27. Illeris, Knud (2006). "Towards a comprehensive theory of human learning." Human Resource Development Review 5(3): 389-391.

28. Jashapara, Ashok (2003). "Cognition, culture and competition: An empirical test of the learning organization." The Learning Organization 10(1): 31.

29. Kauffman, S (1995). At home in the universe: The search for the laws of complexity. London, UK, Viking.

30. Knowles, Malcolm Shepherd, Elwood F. Holton III and Richard A. Swanson (1998). The Adult Learner. USA, Butterworth-Heinemann.

31. Lewin, Roger and Regine Birute (2001). Weaving complexity and business: Engaging the soul at work. NY, USA, Texere LLC.

32. Mant, Alistair (1997). Intelligent leadership. St. Leonards, N.S.W., Allen \& Unwin.

33. McGill, Michael E. and John W. Slocum Jr (1993). "Unlearning the organization." Organizational Dynamics 22(2): 67-79.

34. McLean, Gary N. (2006). "Rethinking adult learning in the workplace." Advances in Developing Human Resources 8(3): 416-423.

35. Merriam, Sharan B. and Rosemary S. Caffarella (1999). Learning in Adulthood: A comprehensive guide. San Francisco, USA, Jossey-Bass Publishers.

36. Nonaka, Ikujiro (1994). "A dynamic theory of organizational knowledge creation." Organization Science $5(1)$.

37. Nonaka, Ikujiro, Georg von Krogh and Sven Voelpel (2006). "Organizational knowledge creation theory: Evolutionary paths and future advances. Review paper." Organizational Studies 27(8): 1179-1208.

38. Phegan, Barry (1996). Developing your company culture: The joy of leadership. Berkeley, California, USA, Context Press, Meridian Group, Inc.

39. Phillips, D.C. (1995). "The good, the bad, and the ugly: The many faces of constructivism." Educational Researcher 24(7): 5-12.

40. Reese, H.W. and W.F. Overton (1970). Models of development and theories of development. Life-span developmental psychology: Research and theory. L. R. Goulet and P. B. Baltes. New York, USA, Academic Press.

41. Schein, Edgar H. (1992). Organisational culture and leadership. San Francisco, California, USA, JosseyBass Inc.

42. Senge, Peter M. (1990b). The fifth discipline: The art and practice of the learning organisation. New York, USA, Doubleday/Currency.

43. Shotter, John (1993). Cultural politics of everyday life. Buckingham UK, Open University Press.

44. Sim, Julius and Chris. Wright (2000). Research in health care: Concepts, designs and methods. Cheltenham, Glos., UK, Stanley Thornes Publishers Ltd.

45. Spencer, Bruce (2002). "Research and the pedagogics of work and learning." Journal of Workplace Learning 14(7/8): 298.

46. Stacey, Ralph (1996a). Complexity and creativity in organizations. San Francisco, USA, Berrett-Koehler Publishers Inc.

47. Stacey, Ralph (1996b). "Emerging strategies for a chaotic environment." Long Range Planning 29(2): $182-$ 189.

48. Stacey, Ralph (2003a). "Learning as an activity of interdependent people." The Learning Organization 10(6): 325-331.

49. Stacey, Ralph D. (2003b). Strategic management \& organisational dynamics: The challenge of complexity. Essex, England, Pearson Education Limited. 
50. Steffe, Leslie P. and Jerry Edward Gale, Eds. (1995). Constructivism in education. Georgia, USA, Hillsdale, N.J.

51. Steiner, Lars (1998). "Organizational dilemmas as barriers to learning." The Learning Organization 5(4): 193-201.

52. Strauss, Anselm L. and Juliet M. Corbin (1990). Basics of qualitative research: Grounded theory procedures and techniques. Newbury Park, Calif., Sage Publications.

53. Tannenbaum, Scott I. (1997). "Enhancing continuous learning: Diagnostic findings from multiple companies." Human Resource Management 36(4): 437.

54. Taylor, David W., Oswald Jones and Kevin Boles (2004). "Building social capital through action learning: an insight into the entrepreneur." Education \& Training 46(4/5): 226-235.

55. Teece, David J., Gary Pisano and Amy Shuen (1997). "Dynamic capabilities and strategic management." Strategic Management Journal 18(7): 509-533.

56. $\quad$ van der Sluis, Lidewey (2002). "Learning behavior and learning opportunities as career stimuli." Journal of Workplace Learning 14(1/2): 19.

57. von Krogh, Georg, Ikujiro Nonaka and Manfred Aben (2001). "Making the most of your company's knowledge: A strategic framework." Long Range Planning 34(4).

58. Wheatley, Margaret J. (1999). Leadership and the new science: Discovering order in a chaotic world. San Francisco, Ca, USA, Berrett-Koehler Publishers, Inc.

59. Whiteley, A.M. (2002). Rigour in qualitative research. Working paper series 02.01. Perth, Australia, Graduate School of Business, Curtin University: 1-37.

60. Whiteley, A.M. (2004). "Grounded research: A modified grounded theory for the business setting." Qualitative Research Journal 4(1): 27-46.

61. Whiteley, Alma (2000). Grounded research: a modified grounded theory for the business setting. Perth, Australia, Curtin University, Graduate School of Business, working paper series 00.02.

62. Zohar, Danah (1994). The quantum society. New York, USA, Quill.

63. Zohar, Danah and Ian Marshall (2004). Spiritual capital: Wealth we can live by. San Francisco, USA, Berrett-Koehler Publishers, Inc. 